\title{
Prevention of Mother-to-Child Transmission (PMTCT) of HIV services in Adama town, Ethiopia: clients' satisfaction and challenges experienced by service providers
}

Anteneh Asefa $^{1 *}$ and Getnet Mitike ${ }^{2}$

\begin{abstract}
Background: The coverage and uptake of prevention of mother-to-child transmission (PMTCT) of HIV services has remained very low in Ethiopia. One of the pillars of improving quality of health services is measuring and addressing client satisfaction. In Ethiopia, information about the quality of PMTCT services regarding client satisfaction is meager.

Methods: A facility-based cross-sectional study using quantitative methods was conducted in Adama town. We interviewed 423 pregnant women and 31 health providers from eight health facilities. Satisfaction of clients was measured using a standard questionnaire adapted from the UNAIDS best practices collection on HIV/AIDS. Bivariate and multivariate logistic regression analyses were used to identify factors associated with clients' satisfaction.

Results: About three-fourth (74.7\%) of clients reported that they were satisfied with the PMTCT services provided by the health facilities. However, a much lower proportion (39\%) of the total respondents (pregnant women who underwent an ANC follow-up session), said they received and understood the messages related to mother-to-child transmission (MTCT) of HIV and PMTCT. The main challenges reported by service providers were lack of training, lack of feedback on job performance and inadequate pay. Clients' satisfaction with PMTCT service was found to be associated with liking the discussion they had with their counselor, non-preference to a different counselor with regards to sex and/or age and not seeing the same ANC counselor before and after HIV test.

Conclusion: Although $74.7 \%$ of clients were satisfied, the majority did not have a good understanding of the counseling on MTCT and PMTCT. We recommend more efforts to be exerted on improving provider-client communication, devising ways of increasing clients' satisfaction and designing an effective motivation strategy for service providers to enhance the status of PMTCT services.
\end{abstract}

\section{Background}

In the year 2011, around 330,000 children acquired HIV infection. This represents a $43 \%$ decline from 560,000 children reported to have been infected with HIV in 2003. More than $90 \%$ of new HIV infection amongst children in the year occurred in Sub-Saharan Africa, home to $92 \%$ of pregnant women living with HIV. Furthermore, only $59 \%$ of pregnant women living with HIV in Sub-Saharan Africa received antiretroviral therapy or prophylaxis in the year 2011 [1]. In Ethiopia, one of the

\footnotetext{
* Correspondence: antex98@yahoo.com

'School of Public and Environmental Health, Hawassa University, Hawassa, Ethiopia

Full list of author information is available at the end of the article
}

countries severely hit by the epidemic, the national HIV prevalence estimate was at $2.1 \%$ in $2010 / 2011$. In the same year, there were around 137,494 new HIV infections, $10 \%$ of which occurred amongst children. Moreover, only $9.3 \%$ of the estimated numbers of HIV positive pregnant women were provided with antiretrovirals (ARVs) for PMTCT in 2011 [2,3].

In Ethiopia, the proportion of HIV positive mothers identified at PMTCT sites has increased from $1.88 \%$ in 2006 to $22.1 \%$ in 2010 and during the same period the number of health facilities providing PMTCT services has shown an 8-fold increment from 171 (21.3\%) to 1,352 (61.9\%) [4]. Among pregnant women who have
C Biomed Central

(c) 2014 Asefa and Mitike; licensee BioMed Central Ltd. This is an Open Access article distributed under the terms of the Creative Commons Attribution License (http://creativecommons.org/licenses/by/2.0), which permits unrestricted use, distribution, and reproduction in any medium, provided the original work is properly credited. 
received antenatal care from those PMTCT service sites, only $75.5 \%$ of them were tested for HIV [2].

Developing and implementing a successful PMTCT program require a comprehensive approach including ensuring availability of minimum number of staff, providing training and cascading a continuum of care for mothers, infants and their families after delivery [5]. Ethiopia adopted its first PMTCT guideline in 2001. Then the second and the third (currently used) guidelines were formulated in 2007 and 2011 respectively $[6,7]$. All guidelines follow the four pronged approach to PMTCT which is recommended by the World Health Organization [8,9]. The Federal Ministry of Health of Ethiopia, recognizing the challenge, has come up with an accelerated plan to guide program implementation and coordination for the coming one year. This emergency approach is intended to rapidly increase service provision sites, improve quality of services and increase utilization so as to reach the ambitious goals set in the health sector development program of providing ARVs for PMTCT to $77 \%$ of eligible pregnant women by 2015 [3,10].

According to the Ethiopian Demographic and Health Survey of 2011, only $9.9 \%$ of mothers deliver at health institutions and only $34 \%$ of mothers receive antenatal care from health professionals [11]. Strengthening the integration of PMTCT services within maternal, newborn and child health $(\mathrm{MNCH})$, sexual and reproductive health, and family planning services in health facilities is one of the critical priorities outlined for reaching the PMTCT targets [3].

One of the pillars of improving quality of health services is measuring and addressing client satisfaction. Thus, this study was conducted to understand the level of satisfaction of clients with PMTCT services and the challenges which providers face in the implementation of PMTCT services in Adama town, Ethiopia. The findings of the study are expected to inform policy makers and providers in their efforts to accelerate the uptake and coverage of PMTCT services through addressing gaps related to clients' satisfaction, providers' perception and services provision.

\section{Methods}

\section{Study design}

A facility-based cross-sectional study which encompassed quantitative methods (client exit interview, and providers' survey) was done in Adama town from March to April 2010.

\section{Study setting}

The study was conducted in Adama town which is the capital of East Shoa zone and which is found 100 kms south of the nation's capital, Addis Ababa. The study was conducted at a government run hospital, three government run health centers, two private hospitals and two private health centers.

\section{Study population}

The study population included selected women who visited the above health institutions for antenatal care services and all PMTCT service providers in those health institutions.

\section{Sample size and sampling}

The sample size for clients' exit interview was determined using a single population proportion formula by taking an assumption that $50 \%$ of the clients would be satisfied by PMTCT services (to get a conservative estimate of the sample size as there was no information on the proportion of clients satisfied with PMTCT services in the country), with $5 \%$ precision, $95 \%$ confidence and possible non-response of $10 \%$. Hence, the calculated sample size was 423 mothers for respondents of the survey amongst clients. On the providers side, all health workers $(n=31)$ who were directly involved with the provision of PMTCT services were included. Allocation of sample to health institutions was made proportionally based on review of the flow of new ANC attendees in each institution in the preceding two weeks of data collection period. Clients were selected by systematic random sampling using clients' registration books from each facility as a sampling frame.

\section{Data collection}

A standardized questionnaire from the UNAIDS best practice collection which basically focuses on HIV/AIDS counseling service assessment was used to assess client satisfaction [12]. The tool was purposively selected since it is the most commonly used tool in low resource settings to generate useful information. The tool inquires information on: mothers' obstetric history, reason for seeking ANC, comfortableness with the way counselors handle clients, presence of the same counselor before and after HIV test, privacy during counseling, topics of discussion during HIV counseling, understandability of messages, and happiness with stay during ANC. Furthermore, other variables (socio-demographic variables, waiting time, the sex of counselor and question merely asking level of satisfaction) were merged with it to gain more contextual understanding of clients' satisfaction. The questionnaire was translated to Amharic and back to English for maintaining consistency. A total of 28 items were included in the exit interview questionnaire.

Health providers were surveyed using a baseline assessment tool for PMTCT service assessment prepared by Family Health International's Institute for HIV/AIDS [13]. The tool was used to assess the level of contribution 
and challenge/s faced by service providers in the provision of PMTCT services.

\section{Data collectors}

Exit interviews with clients were administered by trained data collectors who were female high school graduates. The health providers' survey was conducted by trained clinical nurses.

\section{Data quality assurance}

Pre-testing of the data collection tools was conducted at Bishoftu hospital using $5 \%$ of the total sample size to identify any weakness in the organization and structuring of the research instruments. Bishoftu Hospital is situated in a neighboring town where the population shares similar attributes as that of Adama. Following the pre-test, the tools were improved in terms of their clarity, understandability and simplicity in collecting the data required for the study.

\section{Data analysis and interpretation}

Data were first coded then cleaned and entered using EPI INFO software version 3.5.1. Descriptive frequencies and rating of satisfaction across facilities visited by clients were done using SPSS version 16. Bivariate and multivariate analyses were done to identify factors related to satisfaction. Satisfaction level was assessed using a five level Likert scale (1-very dissatisfied, 2-dissatisfied, 3 -indifferent, 4-satisfied, and 5-very satisfied). To calculate the proportion of satisfied clients, those who responded to be "very satisfied" and "satisfied" were categorized to be satisfied clients and those who responded to be "indifferent", "dissatisfied", and "very dissatisfied" were categorized as unsatisfied.

\section{Ethical considerations}

Ethical clearance was obtained from the Institutional Review Board of Faculty of Medicine, Addis Ababa University. Written permission was obtained from the Oromiya Regional Health Bureau and the institutions in which the study was carried out. Additionally, written consents were obtained from all clients and health providers who participated in the study.

\section{Results}

\section{Socio-demographic and obstetric characteristics of respondents}

A total of 423 ANC attending pregnant women participated in the exit interviews which were carried out to assess the respondents' degree of satisfaction. The sociodemographic characteristic of the clients is described in Table 1 . More than forty one percent $(41.4 \%)$ were in the age group 21-25 years and the mean age was 24.8 years $(S D \pm 4.9$ years). More than ninety percent
Table 1 Socio-demographic characteristics of women who came for ANC services, Adama, March 2010

\begin{tabular}{|c|c|c|c|}
\hline Characteristics & Options & Frequency & Percentage \\
\hline \multirow[t]{5}{*}{ Age in years } & $15-20$ & 95 & 22.5 \\
\hline & $21-25$ & 175 & 41.4 \\
\hline & $26-30$ & 108 & 25.5 \\
\hline & $31-40$ & 44 & 10.4 \\
\hline & 41 and above & 1 & 0.2 \\
\hline \multirow[t]{2}{*}{ Place of residence } & Adama town & 361 & 85.3 \\
\hline & Out of Adama town & 62 & 14.7 \\
\hline \multirow[t]{5}{*}{ Religion } & Orthodox & 252 & 59.6 \\
\hline & Muslim & 96 & 22.7 \\
\hline & Protestant & 67 & 15.8 \\
\hline & Catholic & 5 & 1.2 \\
\hline & Others & 3 & 0.7 \\
\hline \multirow[t]{5}{*}{ Marital status } & Married & 397 & 93.9 \\
\hline & Single & 16 & 3.8 \\
\hline & Divorced & 6 & 1.4 \\
\hline & Widowed & 2 & 0.5 \\
\hline & Separated & 2 & 0.5 \\
\hline \multirow{6}{*}{$\begin{array}{l}\text { Maximum educational } \\
\text { status }\end{array}$} & Illiterate & 60 & 14.2 \\
\hline & $\begin{array}{l}\text { Illiterate but able } \\
\text { to write and read }\end{array}$ & 9 & 2.1 \\
\hline & Grade 1-4 & 101 & 23.9 \\
\hline & Grade 5-8 & 44 & 10.4 \\
\hline & Grade 9-12 & 164 & 38.8 \\
\hline & College and above & 45 & 10.6 \\
\hline \multirow[t]{5}{*}{ Ethnic origin } & Oromo & 158 & 37.4 \\
\hline & Amhara & 141 & 33.3 \\
\hline & Tigre & 28 & 6.6 \\
\hline & Gurage & 75 & 17.7 \\
\hline & Others & 21 & 5.0 \\
\hline \multirow[t]{6}{*}{ Occupational status } & House wife & 268 & 63.4 \\
\hline & Merchant & 40 & 9.5 \\
\hline & $\begin{array}{l}\text { Government } \\
\text { employee }\end{array}$ & 29 & 6.9 \\
\hline & Student & 23 & 5.4 \\
\hline & Daily laborer & 30 & 7.1 \\
\hline & Others & 33 & 7.8 \\
\hline
\end{tabular}

(93.9\%) of the respondents were married. Regarding educational status of clients, $60(14.2 \%)$ of the respondents are illiterate whereas $164(38.8 \%)$ and $45(10.6 \%)$ of the respondents had a secondary school (grade 9-12) and college or more level of education respectively. Of the total mothers interviewed, the majority 223 (52.7\%) of them were in the third trimester of pregnancy while 161 (38.1\%) were in the second trimester of pregnancy. 


\section{Counseling services received by respondents on the date of visit}

On the day of the interview, clients who had undergone counseling were asked about issues related to HIV that were discussed with the antenatal care counselors. The result showed that discussions focused on issues related to undergoing an HIV test, issues related to receiving the results and issues arising from HIV tests taken previously, as confirmed by 209 (49.4\%), 160 (37.8\%), and 186 (44.0\%) of the clients respectively (Table 2 ).

More than half, 220 (52.0\%) of the clients were counseled on MTCT and PMTCT while only $10(2.4 \%)$ of them were counseled on infant feeding. Regarding understandability of the message conveyed during clients' counseling sessions, among clients who received counseling on MTCT/PMTCT $(\mathrm{n}=220), 165(75.0 \%)$ claimed to have understood the message. However, from the total respondents who underwent an ANC follow-up session with health providers $(n=423)$, only $165(39.0 \%)$ received and

Table 2 Pregnant women's reason for coming to the ANC clinics, topics about HIV discussed with ANC attendants, waiting time and pregnant women's number of ANC visits, Adama, March 2010

\begin{tabular}{|c|c|c|}
\hline Characteristics & Frequency & Percentage \\
\hline \multicolumn{3}{|l|}{ Reason for coming to the ANC center } \\
\hline For antenatal care only & 366 & 86.5 \\
\hline To test for HIV & 6 & 1.4 \\
\hline $\begin{array}{l}\text { To receive treatment to protect her } \\
\text { baby from HIV }\end{array}$ & 4 & 1.0 \\
\hline For antenatal care and to test for HIV & 45 & 10.6 \\
\hline $\begin{array}{l}\text { For antenatal care, to test for HIV, To receive } \\
\text { treatment to protect her baby from HIV }\end{array}$ & 2 & 0.5 \\
\hline \multicolumn{3}{|l|}{ Topics discussed with mothers about HIV* } \\
\hline Having an HIV test & 209 & 49.4 \\
\hline Receiving test results & 160 & 37.8 \\
\hline $\begin{array}{l}\text { Issues arising from an HIV test taken } \\
\text { Some time ago }\end{array}$ & 186 & 44.0 \\
\hline MTCT and PMTCT & 220 & 52.0 \\
\hline \multicolumn{3}{|l|}{$\begin{array}{l}\text { Understandability of messages conveyed } \\
\text { on MTCT/PMTCT }(n=220)\end{array}$} \\
\hline Claimed to have understood the messages & 165 & 75.0 \\
\hline $\begin{array}{l}\text { Claimed not to have understood } \\
\text { the messages }\end{array}$ & 55 & 25.0 \\
\hline \multicolumn{3}{|l|}{ Trimester of pregnancy } \\
\hline First & 39 & 9.2 \\
\hline Second & 161 & 38.1 \\
\hline Third & 223 & 52.7 \\
\hline \multicolumn{3}{|l|}{ Waiting time before meeting ANC counselor } \\
\hline$<15$ minutes & 188 & 44.4 \\
\hline$\geq 15$ minutes & 235 & 55.6 \\
\hline
\end{tabular}

*multiple response. claimed to have understood the message on MTCT/ PMTCT (Table 2).

Concerning clients' reasons for coming to ANC service delivery sites, ANC follow-up was mentioned as a primary reason by $86.5 \%$ of respondents. Clients were asked about how they first came to the health institution they visited and more than $61.0 \%$ of them reported that their visit was upon recommendation from their friends or partners. Only $4.0 \%$ of clients came due to referral from other health institutions (Figure 1).

\section{Waiting time experienced by pregnant women}

The mean waiting time for clients to get to the counseling service was 24.5 minutes and the range is calculated to be 359 minutes. When the waiting time was stratified by type of health institution, the waiting time was 21.5 minutes and 41.5 minutes in governmental and in private health institutions respectively. The average duration of stay of clients with their health care provider in the clinics was 12.8 minutes.

\section{Pregnant women's satisfaction with PMTCT services during ANC}

Of the total respondents, $96.0 \%$ reported that they were happy with the session they had during the date of interview. On the other hand, the percentages of women who felt comfortable with their counselor's handling of clients and who perceived presence of enough privacy were $93.4 \%$ and $73.8 \%$ respectively (Table 3 ).

The percentage of clients who were satisfied with PMTCT services during their stay at the service delivery facility on the day of their ANC visit was 74.7\% (71.2\% in public health institutions and $87.8 \%$ in private health institutions) (Figure 2). This proportion includes all those who reported to be very satisfied (34.5\%) and satisfied (40.2\%). Multivariate analysis (logistic regression) controlled for age, education, address, marital status and occupation was carried out to identify variables associated with clients' satisfaction. Pregnant women's satisfaction with PMTCT services was associated with liking the discussion they had with their counselor $[\mathrm{AOR}=0.13$, 95\% CI: 0.04, 0.41], non-preference to a different counselor with regards to sex and/or age $[\mathrm{AOR}=0.04$, 95\% CI: 0.19, 0.82] and not seeing the same ANC counselor before and after HIV test $[\mathrm{AOR}=0.26,95 \%$ CI: 0.12, 0.49] (Table 4).

Work related characteristics reported by service providers All health professionals included in the study $(\mathrm{n}=31)$ work in more than one department and 14 (45.2\%) of them spend most of their time in ANC unit. Among the total providers, $21(67.7 \%)$ were involved in the provision of HIV counseling, 28 (90.3\%) in infant feeding counseling and 29 (93.5\%) in obstetrics care. The average hours spent 


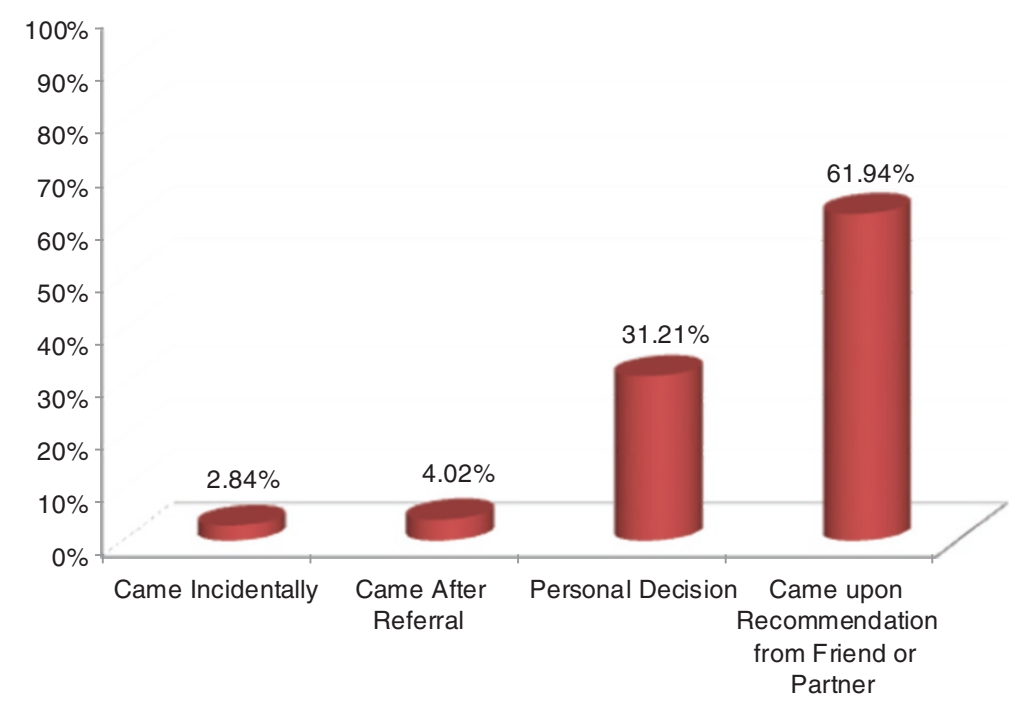

Figure 1 How the pregnant women came to visit the health facility where they had antenatal care for the first time, Adama, March $2010(n=423)$.

per day by providers in counseling MTCT was 5.2 hours and $22(71.0 \%)$ of the providers said that their workload has increased since the introduction of the PMTCT services.

\section{Challenges perceived by service providers in the provision of PMTCT services}

All health providers included in the study (31) reported that there were no incentives for providing PMTCT services. Among health professionals who provide obstetrical care $(n=29)$, twenty one $(72.4 \%)$ of them were trained in safe obstetric practices in caring for HIVpositive women. During the survey, providers were given a set of possible challenges they may encounter in providing PMTCT services and the top three most difficult problems reported to be encountered in performing their job in providing PMTCT related services were lack of feedback on job performance, inadequate pay and lack of training, which were reported by $93.5 \%, 77.4 \%$ and $58.1 \%$ of service providers respectively.

\section{Discussion}

It is known that counseling on MTCT and PMTCT is the most important service out of the services that make up the package of PMTCT services to be offered to all pregnant women visiting ANC clinics. This counseling was offered to $220(52.0 \%)$ pregnant women who were interviewed on the day of their ANC visit. In contrast to our finding, MTCT and PMTCT were discussed on the day of visit for $74.7 \%$ of the pregnant mothers interviewed in Addis Ababa [14]. Among those who have received counseling on MTCT and PMTCT $(\mathrm{n}=220)$ in our study, 165 (75\%) claimed to have understood the message conveyed. However, in the study conducted in Addis Ababa, they only assessed whether the information was received and did not inquire whether clients felt that they understood the messages.

Clients' average waiting time and average duration of stay with their health care provider were 24.5 minutes and 12.8 minutes respectively. This finding was by far better than the report from Kenya. In a PMTCT program in

Table 3 Subjective response of clients towards satisfaction based questions, Adama, March 2010

\begin{tabular}{|c|c|c|c|}
\hline \multirow[t]{2}{*}{ Subjective questions } & \multicolumn{2}{|c|}{ Response } & \multirow[t]{2}{*}{ Total, N (\%) } \\
\hline & Yes, n (\%) & No, n (\%) & \\
\hline Are you happy with the session you had today? & $406(96.0)$ & $17(4.0)$ & $423(100)$ \\
\hline Did you feel comfortable with your counselors handling of the client? & $395(93.4)$ & $28(6.6)$ & $423(100)$ \\
\hline Was there enough privacy during your counseling? & $312(73.8)$ & $111(26.2)$ & $423(100)$ \\
\hline Do you wish you had a different counselor (different sex, older, younger)? & $76(18.0)$ & $347(82.0)$ & $423(100)$ \\
\hline Were you able to see the same counselor for discussion both before and after the test? & $145(34.3)$ & $278(65.7)$ & $423(100)$ \\
\hline Is there anything you did not like during the discussion about HIV/AIDS? & $28(6.6)$ & $395(93.4)$ & $423(100)$ \\
\hline Would you have preferred that HIV/AIDS not be discussed during your antenatal visit? & $20(4.7)$ & $403(95.3)$ & $423(100)$ \\
\hline
\end{tabular}




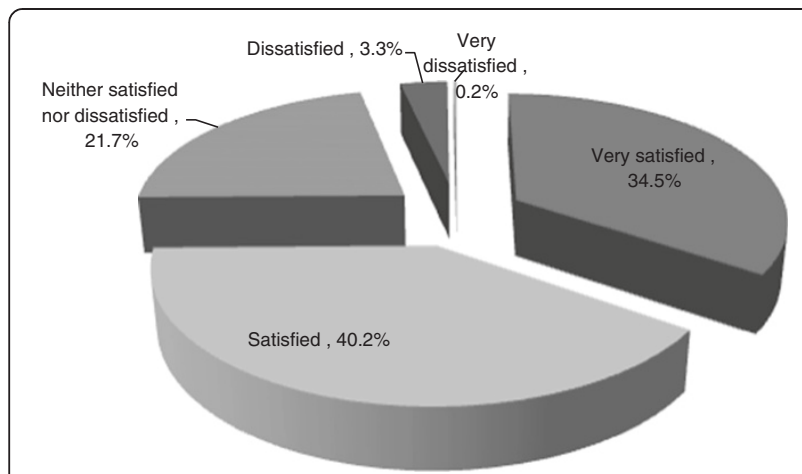

Figure 2 Level of satisfaction of ANC visitors with PMTCT services at the service delivery facilities, Adama, March $2010(n=423)$.

Kenya more than $90.0 \%$ of the clients waited for an average of 150 minutes in addition to the amount of time set by the program guideline for obtaining the services, which is 90 minutes [15].

In this study, there was a preference to be counseled by the same counselor in pre and post test counseling during the ANC visit. These findings might be related to clients' concerns regarding issues of confidentiality. In regards to HIV testing and counseling for PMTCT, it is recommended that the person offering pre-test information provides the post test counseling [16,17]. However, this may be a challenge in many settings of developing countries because of shortage of trained human resource [18].

In this study the level of satisfaction was not affected by either age or sex of the counselor. This may indicate that satisfaction might be more affected by other factors than the socio-demographic characteristics of counselors. In this study, a high proportion (74.7\%) of clients reported that they were satisfied with the service they had received. In this respect, there was no statistically significant difference in satisfaction among clients who experienced waiting time of less than or equal to 15 minutes, and those who had to wait more. However, long waiting time (more than 15 minutes), poor counseling service, and lack of privacy were reported to be the main challenges in the provision of maternal, neonatal, child \& adolescent health services in Ethiopia in the five year period, 2005 to 2010 [10].

This high proportion of satisfied clients might be due to the fact that clients may not report dissatisfaction with services even when services seem to be poor. A research carried out in a university hospital in Brazil also showed that patients generally stated to be satisfied with the rendered service and positively appraised the quality of provided service, that is, even when critical factor that undermined quality of service provision seem to exist [19]. This may over time result in normalization of egregious violations of standards of practice in health care delivery systems [20]. Besides, normalization of disrespect and abuse by individuals and community is identified to be one among the contributors to disrespect and abuse exercised by service providers during maternity health services [21].

In this study, clients who liked the discussion they had with their counselor were less likely to be satisfied with the PMTCT service they received. This surprising finding may be due to the fact that the situations faced by clients at health institutions may not be relevant to them if compared to the quality of attention received which can largely affect their satisfaction [19].

Table 4 Logistic regression analysis of satisfaction by selected explanatory variables, Adama, March 2010

\begin{tabular}{|c|c|c|c|c|}
\hline Explanatory characteristics & Satisfied & Unsatisfied & COR $(95 \% \mathrm{Cl})$ & AOR $(95 \% \mathrm{Cl})$ \\
\hline \multicolumn{5}{|c|}{ Is there anything you did not like during the discussion about HIV/AIDS? } \\
\hline Yes & 17 & 11 & $1.00^{*}$ & \\
\hline No & 299 & 96 & $0.47(0.26,1.10)$ & $0.13(0.04,0.41)^{* *}$ \\
\hline \multicolumn{5}{|c|}{ Do you wish you had a different counselor (different sex, older, younger)? } \\
\hline Yes & 21 & 55 & $1.00^{*}$ & \\
\hline No & 295 & 52 & $0.07(0.04,0.12)^{* *}$ & $0.04(0.19,0.82)^{* *}$ \\
\hline \multicolumn{5}{|c|}{$\begin{array}{l}\text { Were you able to see the same ANC counselor for discussion both before } \\
\text { and after HIV test? }\end{array}$} \\
\hline Yes & 88 & 57 & $1.00^{*}$ & \\
\hline No & 228 & 50 & $0.34(0.26,0.53)^{* *}$ & $0.26(0.12,0.49)^{* *}$ \\
\hline \multicolumn{5}{|c|}{ Waiting time before meeting the ANC counselor } \\
\hline$\leq 15$ minutes & 147 & 41 & $1.00^{*}$ & \\
\hline$>15$ minutes & 169 & 66 & $1.40(0.89,2.19)$ & $1.19(0.66,2.14)$ \\
\hline \multicolumn{5}{|c|}{ Recommended to come to the health institution by others } \\
\hline Yes & 209 & 53 & $1.00^{*}$ & \\
\hline No & 107 & 54 & $1.99(1.26,3.11)^{* *}$ & $1.87(1.00,3.51)$ \\
\hline
\end{tabular}

*Reference group **statistically significant association; Controlled for age, education, residence, marital status and occupation. 
In our study, out of the total PMTCT service providers interviewed, $22(71.0 \%)$ of them said that their workload had increased since the introduction of the PMTCT service and all of them did not get any incentives for providing those PMTCT services. A consultation report from Kenya also validates the fact that the introduction of HIV/AIDS prevention and care into the $\mathrm{MCH}$ setting has meant that health workers have been asked to greatly expand their responsibilities and tasks [18]. Others have reported that the additional responsibilities are rarely accompanied by financial and other types of compensation or that they lead to hasty services that affect the quality of the counseling services $[22,23]$.

This study has deployed a multidimensional approach to understand clients' satisfaction with PMTCT service and challenges experienced by service providers in providing PMTCT service in the study area; however, the scope is limited in addressing all factors which may affect clients' satisfaction and which may pose challenges on service providers. In addition, the study is also limited as it does not look into rural-urban differences.

\section{Conclusions}

This study has shown that clients' satisfaction with PMTCT service was sub-optimal and PMTCT service providers are confronting challenges which can hinder them from providing quality services. Hence, key actors and implementers of PMTCT program need to address bottlenecks which hamper delivery of full package of PMTCT services in line with the national PMTCT guideline. Based on the findings of this study, offering quality counseling on MTCT and PMTCT to all pregnant women, strengthening providers' capacity and motivation technique to help them deliver quality, comprehensive PMTCT interventions are recommended. Furthermore, improving provider-client communication and devising ways of increasing clients' satisfaction with PMTCT services is advised.

\section{Competing interests}

The authors declare that they have no competing interests.

\section{Authors' contributions}

Both authors contributed equally to this work.

\section{Acknowledgements}

We are indebted to the Ethiopian Public Health Association (EPHA) for financing this research. We deeply acknowledge Mr. Yoseph W/Gebriel from USAID for his unreserved support during our research activities. We extend our thanks to the staff of Oromiya Regional Health Bureau, Adama Special Zone Health Office, all the other health institutions and participants of the study.

\section{Author details}

${ }^{1}$ School of Public and Environmental Health, Hawassa University, Hawassa, Ethiopia. ${ }^{2}$ School of Public Health, Addis Ababa University, Addis Ababa, Ethiopia.

Received: 19 March 2013 Accepted: 28 January 2014

Published: 1 February 2014

\section{References}

1. UNAIDS: Report on the Global AIDS Epidemic. Geneva: Joint United Nations Programme on HIV/AIDS; 2012

2. Federal Ministry of Health: Health and Health-related Indicators Report for EFY 2003. Addis Ababa: Federal Ministry of Health; 2009.

3. Federal Ministry of Health: Accelerated Plan for Scaling Up Prevention of Mother to Child Transmission (PMTCT) Services in Ethiopia. Addis Ababa: Federal Ministry of Health; 2011.

4. Nigatu T, Woldegebriel Y: Analysis of the Prevention of Mother-to-Child Transmission (PMTCT) Service Utilization in Ethiopia: 2006-2010. Reprod Health 2011, 8:6.

5. Perez F, Orne-Gliemann J, Mukotekwa T, Miller A, Glenshaw M, Mahomva A, Dabis F: Prevention of mother to child transmission of HIV: evaluation of a pilot programme in a district Hospital in Rural Zimbabawe. BMJ 2004, 13:1147-1150

6. Federal HIV/AIDS Prevention and Control Office: Prevention of Mother to Child Transmission of HIV. Addis Ababa: Federal Ministry of Health; 2001.

7. Federal HIV/AIDS Prevention and Control Office: Prevention of Mother to Child Transmission of HIV. Addis Ababa: Federal Ministry of Health; 2007.

8. Federal HIV/AIDS Prevention and Control Office: Guidelines for Prevention of Mother-to-Child Transmission of HIV in Ethiopia. Addis Ababa: Federal Ministry of Health; 2011. http://www.etharc.org/, Accessed on August 30, 2013.

9. World Health Organization: Prevention of Mother-to-Child Transmission of HIV; HIV Technical Briefs For use. Geneva: World Health Organization; 2007.

10. Federal Ministry of Health: The Ethiopian Health Sector Development Program IV, 2010/11-2014/15. Addis Ababa: Federal Ministry of Health; 2010.

11. Central Statistical Agency: Ethiopian Demographic and Health Survey, 2011. Addis Ababa: Central Statistical Agency; 2012.

12. UNAIDS: Tools for Evaluating HIV Voluntary Counseling and Testing; Joint United Nations Programme on HIV/AIDS. Geneva: Joint United Nations Programme on HIV/AIDS; 2000. http://www.unaids.org/, Accessed online on September 03, 2009

13. Family Health International, Institute for HIV/AIDS: Baseline assessment tools for Preventing Mother-to-Child Transmission (PMTCT) of HIV. USA: Family Health International; 2003. http://www.fhi.org/, Accessed online on September 03, 2009.

14. Ismail H: Assessment of Quality of Antenatal-linked HIV Counseling and Testing for Intervention of PMTCT of HIV in Addis Ababa, Masters Thesis. Addis Ababa University, School of Public Health; 2008. http://www.aau.edu.et/, Accessed on June 01, 2011

15. Moth IA, Ayayo ABCO, Kaseje DO: Assessment of Utilization of PMTCT of HIV in Nyanza Provincial Hospital, Kenya. J Soc Aspects HIV/AIDS 2005, 2:245-250.

16. CDC: Revised Guidelines for HIV Counseling, Testing, and Referral and Revised Recommendations for HIV Screening of Pregnant Women. Atlanta: Atlanta: Center for Disease Control; 2001.

17. CDC: Testing and Counseling for Prevention of Mother-to-Child Transmission of HIV (TC for PMTCT). Centers for Disease Control and Prevention, Reference Guide. Atlanta: Atlanta: Center for Disease Control; 2006

18. The Population Council: Integrating HIV Prevention and Care into Maternal and Child Health Care Settings: Lessons Learned from Horizons Studies. Maasai Mara and Nairobi, Kenya. Consultation report. Washington DC: The Population Council; 2001.

19. Oliveira FD, Arieta EC, Temporini RE, Jose KN: Quality of health care: patient satisfaction in a University Hospital. Arq Bras Oftalmol 2006, 69(5):731-736. http://www.scielo.br/pdf/abo/v69n5.pdf/, Accessed on August 25, 2013.

20. Banja J: The normalization of deviance in health care delivery. Bus Horiz 2010, 53(2):139.

21. USAID, Translating Research into Action: Exploring Evidence for Disrespect and Abuse in Facility-Based Childbirth: Report of a Landscape Analysis. New York: USAID; 2010

22. UNICEF: Evaluation of United Nations Supported Pilot Projects for the Prevention of Mother-to-Child Transmission of HIV. Overview of Findings. New York: USAID; 2003.

23. Falaes EJ, Tylleskart T, De Paoli MM, Manongi R, Engebresten IMS: Mothers' Knowledge and Utilization of Prevention of Mother-to-Child Transmission Services in Northern Tanzania. J Int AIDS Soc 2010, 13:36-41.

doi:10.1186/1471-2393-14-57

Cite this article as: Asefa and Mitike: Prevention of Mother-to-Child Transmission (PMTCT) of HIV services in Adama town, Ethiopia: clients satisfaction and challenges experienced by service providers. BMC Pregnancy and Childbirth 2014 14:57. 